\title{
SPATIAL AND TEMPORAL CHANGES OF VEGETATION COVER IN CHINA BASED ON MODIS NDVI
}

\author{
KASORO, F. R. ${ }^{1}-$ YAN, L. $^{1 *}-$ ZHANG, W. $.^{*}-$ ASANTE-BADU, B. ${ }^{1}$ \\ ${ }^{I}$ College of Resources and Environment Sciences, Jilin Agricultural University, Changchun, PR \\ China \\ ${ }^{2}$ Research Center for Total Emission Control and Trading of CAEP, Chinese Academy for \\ Environmental Planning, Beijing 100000, China \\ *Corresponding authors \\ e-mail/phone/fax: yanlijau@163.com/+86-155-2686-6351; lunwen201906@163.com
}

(Received $17^{\text {th }}$ Nov 2020; accepted $8^{\text {th }}$ Feb 2021)

\begin{abstract}
Vegetation in China experienced serious threat from several driving forces such as population growth and anthropogenic activities. Real-time mapping and assessment of yearly vegetation cover is vital to understand environmental conditions. Here, we examined the trend of vegetation cover changes in China over a 15-year period using remote sensed data. To achieve this, we reclassified the Normalized Difference Vegetation Index (NDVI) values into four classes: No, Low, Medium, and High covers and proceeded to vegetation change detection. The results indicated a difference in values at each level. At the national level, there is an increase in vegetation cover as reflected by High cover class with $41.03 \%$ in 2015. At the regional level, the most significant changes were determined in the south where the rate of green cover was declining by $-63622.3 \mathrm{~km}^{2}$ from 2000 to 2015 in the High cover class. Vegetation cover changes varied from province to province. Some provinces showed a reduction in vegetation cover such as Guangdong; whereas Xinjiang experienced an increase (Tables Al and A2). The findings of this study provide further information on China's vegetation cover and will also serve as reference for future research.
\end{abstract}

Keywords: remote sensing, satellites, monitoring, forest, environment

\section{Introduction}

In the past decades, the Earth has experienced fast population growth which has led to a rise in demand and supply for consumer goods and products thereby leading to an overuse of natural resources from the ecosystem (Hutchinson, 1969; FAO, 1997; Li et al., 2013b; Obienusi et al., 2014). Consequently, this has exerted significant pressure on the ecosystem which in turn has led to a series of environmental issues such as soil erosion from water runoff (Arima et al., 2005), pollution through industrial emission of hazardous substances (Caldas et al., 2007) or soil degradation from intensive use of pesticides (Pacheco and Poccard-Chapuis, 2012) and fertilizers (Kaimowitz and Angelsen, 1998). Furthermore, issues of deforestation (resulting from excessive logging, bush fire, agricultural activities, urbanization) (Islam et al., 2018; Lambin, 1994), energy generation (Ratcliffe, 1984; Sasaki and Takahara, 2011) and tourism (Burden and Randerson, 1972; Kerbiriou et al., 2008; Lucas-Borja et al., 2011) are high. All these activities lead to a reduction in the quantity and quality of natural resources available in the ecosystem (Vitousek et al., 1997). Globally, research has proven that vegetation cover that has undergone pressure from anthropogenic activities is more significant than vegetation without pressure (Zubair, 2006; Jacinthe and Lal, 2006; Wang et al., 2014). In addition, changes in vegetation cover have a more important 
effect on the ecosystem than changes in climatic factors (Jensen, 1996) and China is equally affected by these pressures on the ecosystem.

China is a leading country in technology, industrial development and has the largest population over the world (United Nations, 2017). From the 1970s, the country has undoubtedly undergone rapid economic expansions and urbanization (Wang, 2010) and has managed to take a great number of its population out of poverty. According to Yan et al. (2017), China's population explosion has led an alarming expansion of urban areas from $17.92 \%$ in 1978 to $57.35 \%$ in 2016 and was projected by the National Bureau of Statistics of the People's Republic of China to reach 60\% in 2020. Despite the great benefit behind the development of China, the effect of the development on the ecosystem has caused an alarming degradation level. For instance, mining projects have negatively affected the vegetation and contributed to spatial changes in Pingshuo opencast coal mining located in Shanxi province (Zhang et al., 2019). In addition, some research have observed deficit in ecosystem resources and an important green land transformation in built up areas, agricultural land, opencast mining, and barren land which have largely influenced the decrease in vegetation cover (Zhang et al., 2007; Wang, 2010).

Owing to the complex situation of vegetation cover changes in China, the government implemented several laws and policies on ecosystem protection mainly for vegetation conservation. According to some studies, the country has financed several projects with the amount of 354 billion Yuan from 1999 to 2003 and with 1636 billion Yuan for environmental restoration and protection from the year 2003 to 2008 (Kauppi et al., 2006; Piao et al., 2009; Liang et al., 2018). The results of all these attempts have been positive in several provinces with a significant vegetation growth and reduction of degradation of the ecosystem. Nevertheless, permanent monitoring and mapping of vegetation cover dynamic at different scales is important in order to predict the future state, understand and assess the development and changes that occur as a consequence of human activities (Bozkaya et al., 2015; Gu et al., 2016; Weng, 2001; Mao et al., 2011; Mu et al., 2012; Mooney et al., 2013; Sterling et al., 2013).

Several methods were applied in some studies for analyzing the trend of vegetation cover and were mainly based on traditional surface measurement methods with a mandatory field observation (Liu et al., 2018). These methods have good precision, however, they showed limitations due to high cost and the results are often personal to the data collector (Wei et al., 2006) when the study is on a large scale (Lu, 2006; Bao et al., 2014; Zhou et al., 2015). Therefore, other methods have emerged such as remote sensing with the benefits of brief sampling time, dynamic data, wide scale cover, spectral resolution, and minimal costs (Gillespie et al., 2018; Zoungrana et al., 2018). Remote sensing becomes a method widely adopted and applied in land survey and vegetation cover analysis because of its ability to offer multi-spatial and temporal crop cover changes (Zhang and $\mathrm{Wu}, 2015)$. Furthermore, it has been given free access on earth data with a great amelioration on methods analysis (Gutman et al., 2013).

Recently, there has been growing interest in the use of Moderate Resolution Imaging Spectroradiometer (MODIS) NDVI data for land cover analysis and monitoring especially vegetation cover (Beck et al., 2006; Lunetta et al., 2006; Jacquin et al., 2010; Louise et al., 2014; Usman et al., 2015; Zoungrana et al., 2018). MODIS NDVI products have been mostly used in studies over large surface areas compared to other NDVI products such as VEGETATION instrument on Satellite Pour l'Observation de la Terre (SPOT VGT) and National Oceanic Aeronautic Administration Advanced Very 
High-Resolution Radiometer (NOAA-AVHRR) NDVI (Fensholt and Sandholt, 2005; Fensholt et al., 2006). They have high-sensitivity radiometric information in 36 spectral bands allowing in-depth perception of the changes that happened in the different components of land cover (Wang et al., 2013). In addition, they have three different spatial resolutions which are $250 \mathrm{~m}, 500 \mathrm{~m}$ and $1000 \mathrm{~m}$ making it possible to achieve studies at different scales (Skole et al., 1997; Janetos and Justice, 2000). Since MODIS NDVI products provide spatial resolution, surface anisotropy, calibration, atmosphere correction, grid protection, vegetation sensitivity and cloud detection, they are considered as one of the most sophisticated remote sensing data images and mostly used in land cover monitoring (Yan et al., 2013). Furthermore, the NDVI contained in the MODIS data is described as a quantitative index which explains the health of vegetation cover by using the near infrared and visible band (Carlson and Ripley, 1997) and it is among the most applied indices for monitoring changes in vegetation cover (Scanlon et al., 2002; Yang et al., 2012; Zhang et al., 2018).

Investigations carried out by several authors (Liping et al., 2018; Xu et al., 2018), applied remote sensing techniques to assess the global trend of vegetation cover changes, including China. Their findings showed how remote sensing is a reliable method to understand land cover changes by providing accurate information on vegetation changes. Going further, numerous studies have used vegetation indices to detect the vegetation cover changes which were limited to either provincial or regional levels in China (Mu et al., 2012; Li et al., 2013b; Zhang et al., 2017). However, few of them have assessed the spatial and temporal changes in vegetation at three levels in China using MODIS NDVI time series. Therefore, our study provides useful information on vegetation cover trend for provincial, regional, and national levels.

Thus, the current research attempts to assess spatial and temporal changes of vegetation cover throughout China using MODIS NDVI data products over a 15 -year period from 2000 to 2015. As a move in this direction, we hope that this research could be used as a starting point for further studies which intense will help local policymakers in environmental sustainability.

\section{Review of literature}

Vegetation cover is considered as a key constituent of the ecosystem and covers almost $70 \%$ of the earth land cover (Arellano et al., 2015; Veraverbeke et al., 2012; Zhou et al., 2015; Peng et al., 2015). It plays a major role in biogeochemical and hydrological cycles. Additionally, it connects with others natural constituents of the environment such as soil, water, and the atmosphere (Piao et al., 2003). Several environmental services and functions such as carbon sequestration, water and soil sustentation, air purification, and preservation of biodiversity are provided by vegetation which is important for all living things on the earth (Sheram, 1993; Wang et al., 2012). Vegetation cover is also an indicator of any change that occurs in the ecosystem (Lambin and Strahler, 1994). Furthermore, vegetation is one of the key elements in climate change mitigation and the reduction of greenhouse gases (Caputo, 2009; Moroni, 2013) and portrays an important function in the conservation and regulation of environmental quality (Piao et al., 2011; Peng et al., 2012; Yan et al., 2017). 


\section{Materials and methods}

\section{Description of the study area}

The study was conducted in the People's Republic of China (PRC) which is the third largest country in the world with 9.6 million $\mathrm{km}^{2}$ with almost $21 \%$ of the global population. China is located in the east side of Asia, between $73^{\circ} 33^{\prime} \mathrm{E}-135^{\circ} 05^{\prime} \mathrm{E}$ and $3^{\circ} 51^{\prime} \mathrm{N}-53^{\circ} 33^{\prime} \mathrm{N}$ (Fig. 1).

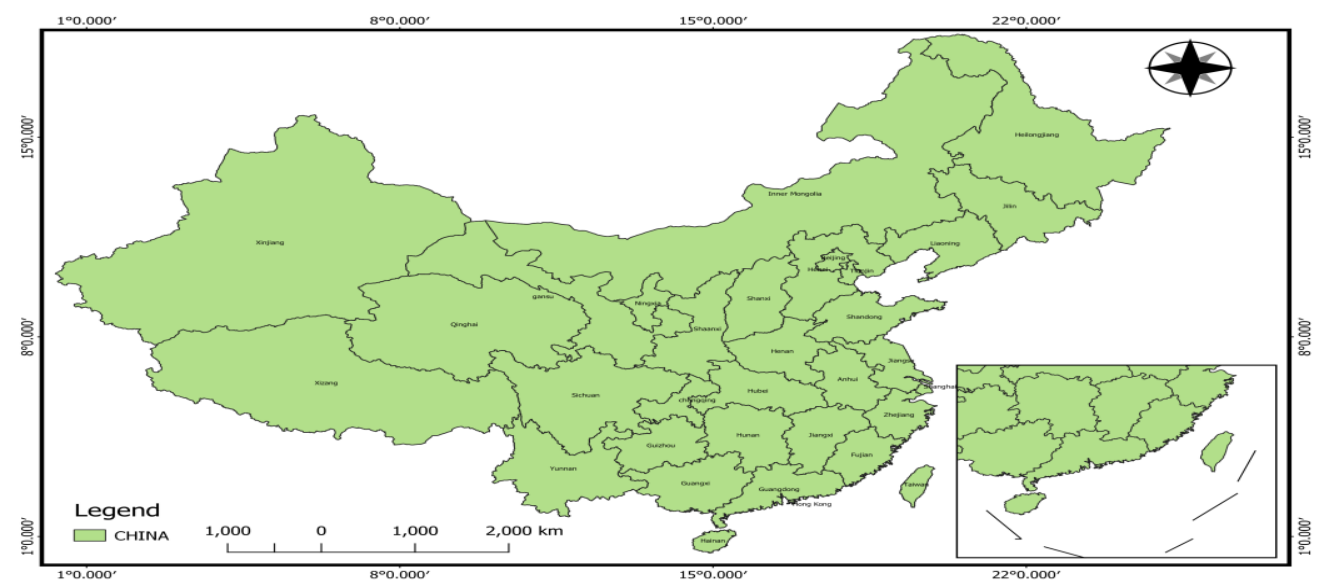

Figure 1. Overview of the study area

China is covered by mountains, plateaus, valleys, plains and hills. The administrative subdivision of China is as follows: 4 municipalities, 5 autonomous regions and 23 provinces, as well as Macao and Hong Kong which are considered as special territories.

The study area has four main agro-climatic zones: the semi-humid zone and the humid zone in the southern and southwestern part of China, the arid zone in the western and northwestern, and the semi-arid zone in the central. Heavy rainy season extends in the northern part from June to September and in the southern part from April to August.

The average annual rainfall is estimated at $645 \mathrm{~mm}$ but may reach 1000 to $2000 \mathrm{~mm}$ in the southeast and southwest coastal regions. The research area has an abundant sunlight and radiation estimated between 3200 and $3300 \mathrm{~h}$. China has a very diverse flora and is considered as one of the countries with the richest vegetation on the planet.

Our study was conducted on three scales: the national, regional, and provincial levels as described in Table 1. Table 1 shows the description of different China's regions. The Special Territory of Macao was not analyzed as part of this research due to a lack of information and data.

\section{Data source}

In this research, the data used to assess the trends in vegetation in China over a fifteen-year period was MODIS NDVI data (MODND1M). The selected MODIS NDVI data was obtained from the web interface http://www.gscloud.cn./ and was presented by the satellite in a gridded appearance with a sinusoidal or periodic projection. The spatial resolution of the collected data was $500 \mathrm{~m}$ with a temporal resolution of 32 days.

The selected data of the years 2000, 2005, 2010, and 2015 were collected during summer in June because vegetation cover is usually varying accordingly to seasonal 
factors which is favorable to generate a better reflectance in that period of the year, marked by the growing season in China.

Table 1. Description of regions and provinces with their climate and terrain information

\begin{tabular}{|c|c|c|c|}
\hline Regions & Provinces & Climate & Topography \\
\hline $\mathrm{N}$ & $\begin{array}{c}\text { Inner Mongolia, Beijing, Tianjin, Shanxi, and } \\
\text { Hebei }\end{array}$ & $\begin{array}{l}\text { Semi-humid } \\
\text { continental monsoon }\end{array}$ & $\begin{array}{l}\text { Mountains, plains, } \\
\text { and plateaus }\end{array}$ \\
\hline $\mathrm{E}$ & $\begin{array}{l}\text { Anhui, Fujian, Jiangxi, Jiangsu, Shandong, } \\
\text { Shanghai, Taiwan, and Zhejiang }\end{array}$ & $\begin{array}{l}\text { Subtropical monsoon } \\
\text { humid }\end{array}$ & $\begin{array}{l}\text { Plains, hills, and } \\
\text { mountains }\end{array}$ \\
\hline N-E & Jilin Heilongjiang, and Shenyang & $\begin{array}{c}\text { Temperate continental } \\
\text { monsoon }\end{array}$ & $\begin{array}{l}\text { Mountains and } \\
\text { hills }\end{array}$ \\
\hline $\mathrm{N}-\mathrm{W}$ & Xinjiang, Qinghai, Gansu, Shaanxi, and Ningxia & $\begin{array}{c}\text { Semi-humid } \\
\text { continental monsoon }\end{array}$ & $\begin{array}{c}\text { Mountains and } \\
\text { plateaus }\end{array}$ \\
\hline S & Hong Kong, Hainan, Guangdong, and Guangxi & $\begin{array}{l}\text { Subtropical and } \\
\text { tropical monsoon }\end{array}$ & $\begin{array}{l}\text { Hills, plains, } \\
\text { mountains, and } \\
\text { plateaus }\end{array}$ \\
\hline S-W & $\begin{array}{c}\text { Sichuan, Yunnan, Guizhou, Chongqing and } \\
\text { Xizang }\end{array}$ & $\begin{array}{l}\text { Subtropical wet } \\
\text { monsoon }\end{array}$ & $\begin{array}{l}\text { Hills, mountains, } \\
\text { and plateaus }\end{array}$ \\
\hline $\mathrm{S}-\mathrm{C}$ & Hubei, Hunan, and Henan & Subtropical monsoon & $\begin{array}{l}\text { Mountains and } \\
\text { plains }\end{array}$ \\
\hline
\end{tabular}

$\mathrm{N}$ is north; $\mathrm{E}$ is east; N-E is northeast; N-W is northwest; $\mathrm{S}$ is south; $\mathrm{S}-\mathrm{W}$ is southwest; $\mathrm{S}-\mathrm{C}$ : south central

\section{Data analysis}

The selected MODIS NDVI data from the years 2000, 2005, 2010 and 2015 were clipped, extracted from all China (provinces and regions), projected with the Xian 1981 coordinate system using ArcGIS 10.5 software. Moreover, the reclassification of the images was performed based on the NDVI value of each pixel into four classes No, Low, Medium and High cover, respectively (Hashim et al., 2019; Sahebjalal and Dashtekian, 2013). The NDVI value is estimated between -1 and +1 , the highest value showed a greener cover and the lowest for a barren land, urbanized or water areas (Madonsela et al., 2018). The NDVI is often determined with the following formula (Eq. 1) by Tucker (1979):

$$
\mathrm{NDVI}=\frac{(\mathrm{NIR}-\mathrm{RED})}{(\mathrm{NIR}+\mathrm{RED})}
$$

where $R E D$ is the value of reflectance of red band and NIR is the near infrared band.

As described in Table 2, the NDVI values for the study area range from 0.1 to 0.9 . Thus, after the reclassification of the NDVI images for the years 2000, 2005, 2010 and 2015, the new land cover maps for the different corresponding years were produced using ArcGIS 10.5 and QGIS 3.

\section{Vegetation cover change analysis}

Change detection images time series is a remote sensing method applied to estimate and locate changes occurred in a study area. This method is mainly established on the comparison of the spectral change of the image between two time periods (Eqs. 3 and 4). 
It is widely used and is very useful for vegetation cover change studies ( $\mathrm{Lu}$ et al., 2004; Coppin et al., 2004; Kashaigili et al., 2006).

Table 2. NDVI density classes

\begin{tabular}{c|c|c}
\hline Vegetation classes & Description & Vegetation cover (NDVI) \\
\hline No vegetation & Barren land, built up areas, road network and water & $<0.1$ \\
Low vegetation & Shrub land & $0.1-0.3$ \\
Medium vegetation & Grassland and agriculture land & $0.3-0.6$ \\
High vegetation & Forest land & $0.6-0.9$ \\
\hline
\end{tabular}

In this research, change detection analysis was conducted to understand the trend of spatial variations in vegetation cover in fifteen years.

As a result, the trend of change of each class and year were calculated in $\mathrm{km}^{2}$ and then converted to percentages (\%) as shown in Equation 2. The results obtained helped to detect and identify changes occurred in China on three different scales. The percentage rate of each class was calculated by:

$$
n=\frac{A * 100}{s}
$$

where $n$ was the percentage rate of each class, $A$ was surface area of each class and $S$ was the total surface area in $\mathrm{km}^{2}$.

Percent area change between the two periods (2000 and 2015) was calculated according to the following equation:

$$
P A C=(\Delta A / T) * 100
$$

where $P A C$ corresponds to the Percent area change, $\triangle A$ was the value of the final and initial years $\left(\mathrm{a}_{2}-\mathrm{a}_{1}\right)$, and $T$ was total area of the study area.

Percent annual rate $(P A R)$ of change was estimated by the formula:

$$
P A R=(\Delta A / T * 100) / n
$$

where $n$ denote the number of years between the initial and final years

\section{Results}

\section{Spatial variation of vegetation coverage classes from 2000 to 2015 at national level}

Following the NDVI density classes in Table 2, the spatial and temporal changes of vegetation cover were revealed from the year 2000 to 2015. As shown in Table 3, the results demonstrated that in 2000,17.75\% of the land cover in China was found to be in No cover class (barren land, water, road network, and built-up areas). Notwithstanding, in 2005, 2010 and 2015 of the same class, results showed a change of $17.43 \%, 15.50 \%$ and $15.15 \%$, respectively. The Low class characterized by shrub land experienced a saw-tooth dynamic, increase, and decrease during the fifteen years of study with $21.21 \%$ in 2000 and $20.72 \%$ in 2015, respectively. However, the Medium and High 
classes showed a significant rise in the area of vegetation with $22.60 \%$ in 2000 and $23.10 \%$ in 2015 , and $38.44 \%$ in 2000 and $41.03 \%$ in 2015 , respectively.

The results in Table 3 indicate the change in vegetation cover area from 2000 to 2015. It showed that the No cover and Low cover classes lost $2.61 \%$ and $0.49 \%$ respectively, i.e., $-248679.97 \mathrm{~km}^{2}$ and $-46629.71 \mathrm{~km}^{2}$ of surface area. In contrast, the Medium and High classes gained a $0.61 \%$ and $2.36 \%$ respectively, i.e., $48259.71 \mathrm{~km}^{2}$ and $246341.28 \mathrm{~km}^{2}$. All these results may reveal that forests and grasslands have increased slightly while barren land or shrub lands areas have decreased. Further information is also demonstrated in Figure 2.

Table 3. Evolution of vegetation cover from 2000 to 2015

\begin{tabular}{|c|c|c|c|c|c|c|c|c|c|c|c|}
\hline \multirow{3}{*}{$\begin{array}{c}\text { Types of } \\
\text { vegetation }\end{array}$} & \multicolumn{8}{|c|}{ Spatial area cover } & \multirow{2}{*}{\multicolumn{2}{|c|}{$\begin{array}{l}\text { Change area } \\
(2000-2015)\end{array}$}} & \multirow{3}{*}{\begin{tabular}{|c|}
$\begin{array}{c}\text { The annual rate of } \\
\text { change }(2000-2015)\end{array}$ \\
$\mathrm{km}^{2} /$ year \\
\end{tabular}} \\
\hline & \multicolumn{2}{|l|}{2000} & \multicolumn{2}{|l|}{2005} & \multicolumn{2}{|l|}{2010} & \multicolumn{2}{|l|}{2015} & & & \\
\hline & Area $\left(\mathbf{k m}^{2}\right)$ & $\%$ & Area $\left(\mathbf{k m}^{2}\right)$ & $\%$ & Area $\left(\mathbf{k m}^{2}\right)$ & $\%$ & Area $\left(\mathbf{k m}^{2}\right)$ & $\%$ & Area $\left(\mathbf{k m}^{2}\right)$ & PAC & \\
\hline No & 1693988 & 17.75 & 1662832 & 17.43 & 1479306 & 15.5 & 1445309 & 15.15 & -248679 & 2.61 & 0.17 \\
\hline Low & & 21.21 & 2024872 & 21.22 & & 21.62 & & 20.72 & & 0.49 & 0.03 \\
\hline Medium & 2156018 & 22.6 & 2241893 & 23.49 & 2296709 & 24.07 & 2204278 & 23.1 & 48259.7 & 0.61 & 0.04 \\
\hline High & 3668111 & 38.44 & 3613107 & 37.86 & 3702681 & 38.8 & 3914452 & 41.03 & 246341 & 2.36 & 0.16 \\
\hline
\end{tabular}
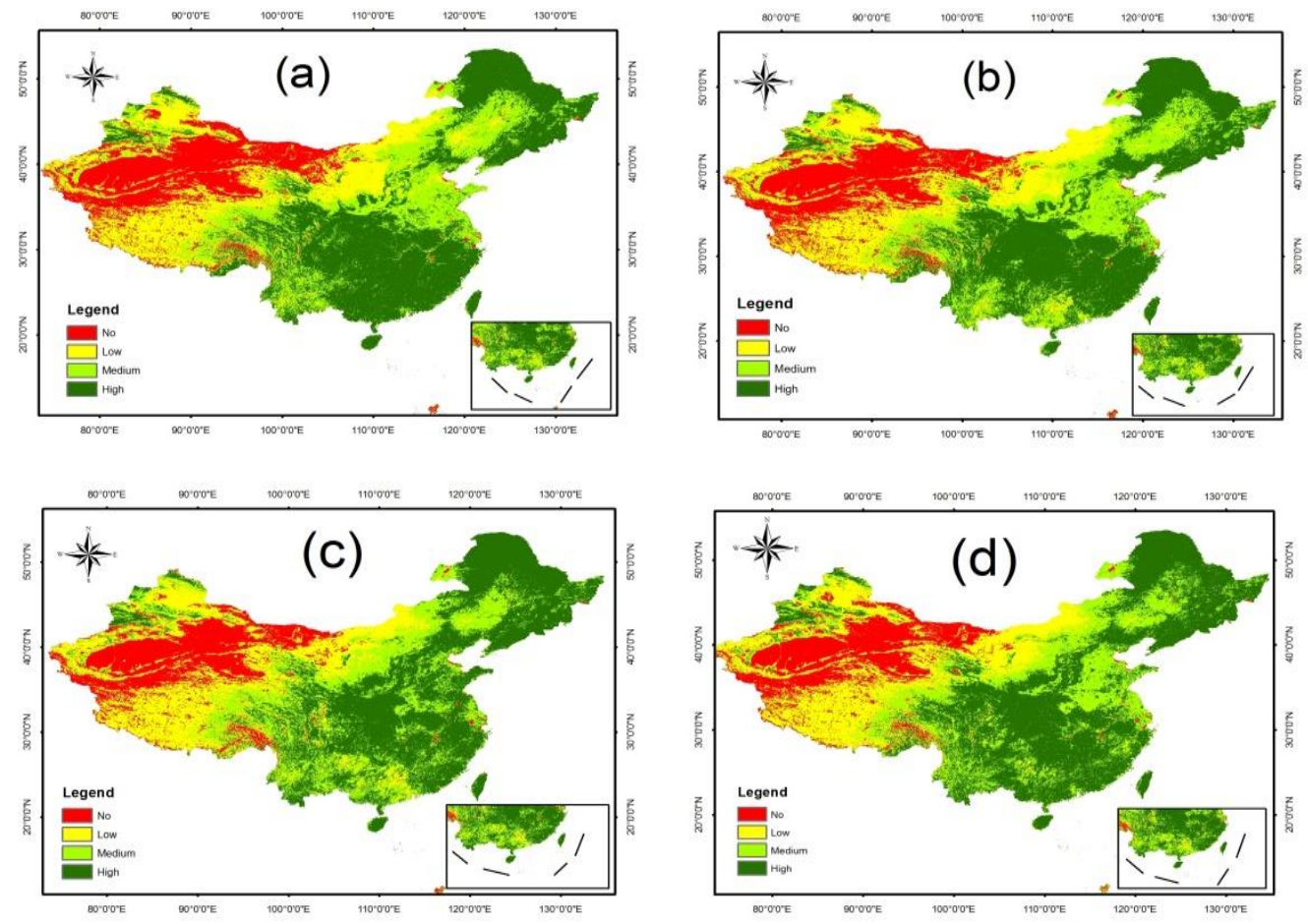

Figure 2. The vegetation cover maps for the year (a) 2000, (b) 2005, (c)2010 and (d) 2015

\section{Spatial and temporal trend analysis (2000-2015)}

Trend in changes of vegetation cover over the period of 2000 to 2015 at regional level

Table 4 shows variation of vegetation cover over 2000 through 2005 and 2005 through 2010. The findings for 2000 to 2005, showed that the southwestern and the 
southern were highest in values in terms of No cover class with $44946.27 \mathrm{~km}^{2}$ and $1080 \mathrm{~km}^{2}$ respectively. However, in the northwestern and northern regions there were reduction of No cover class areas for the same period with $-43528.9 \mathrm{~km}^{2}$ and $34278 \mathrm{~km}^{2}$. In addition, for the same period the results revealed a significant decrease in High cover class in the south-central region with $-21475.5 \mathrm{~km}^{2}$.

Similarly, the results of the 2005-2010 are presented in the same Table 4. It was observed that most regions such as the northern, northwestern and southwestern the amount of No cover areas were significantly reduced hence these could be converted to Low, Medium or High cover classes. Obviously, most of the regions revealed an increase in vegetation cover; with the exception of southern and southwestern regions which detected a decrease in High cover with $-21391.9 \mathrm{~km}^{2}$ and $-226147 \mathrm{~km}^{2}$, accordingly.

Comparing the results of both 2000-2005 and 2005-2010 in Table 4, the study reveals that from 2000 to 2010, there was positive improvement of vegetation cover areas in most of the regions, even though, there were few instances where reduction occurred.

Table 4. Statistics of vegetation cover from 2000 to 2005 and from 2005 to 2010 at regional scale

\begin{tabular}{c|c|c|c|c|c|c|c|c}
\hline \multirow{2}{*}{ Regions } & \multicolumn{4}{|c|}{$\mathbf{2 0 0 0 - 2 0 0 5}$} & \multicolumn{3}{c}{$\mathbf{2 0 0 5 - 2 0 1 0}$} \\
\cline { 2 - 8 } & No & Low & Medium & High & No & Low & Medium & High \\
\hline N & -34278 & -14262 & -11363 & 60002 & -44479.5 & -77161.9 & -14455.6 & 136124 \\
E & 938 & -5345 & -12127 & 16466 & -377.18 & 3111.15 & -84532.8 & 81834.82 \\
NE & -475.84 & -8659.63 & -8158.72 & 18307.48 & -457.81 & 6193.9 & -86495.7 & 92139.94 \\
NW & -43528.9 & 18753.2 & 17384.88 & 7393.1 & -94915.9 & -38133.2 & 106460.2 & 26577.35 \\
S & 1080.18 & 40403.64 & 133853.6 & -175378 & 760.43 & 7248.51 & 13367.62 & -21391.9 \\
SW & 44946.27 & -32154.7 & -52470.7 & 39676.16 & -44307.1 & 143808.6 & 126592.7 & -226147 \\
SC & 162.92 & 2529.1 & 18776.07 & -21475.5 & 250.42 & 5457.88 & 6139.24 & 437.12 \\
\hline
\end{tabular}

The statistic of vegetation changes is estimated from 2010 to 2015 and from 2000 to 2015 at regional level in China (Table 5). Based on the results of 2010 to 2015, the northwestern, northern and southern regions experienced a reduction in No cover areas with $-7846.14 \mathrm{~km}^{2},-4070.48 \mathrm{~km}^{2},-1686.47 \mathrm{~km}^{2}$; whereas the southwestern and northeastern had an increase in No cover areas with $24165.9 \mathrm{~km}^{2}$ and $2608.59 \mathrm{~km}^{2}$. Our findings also showed that in High cover class, that is, southern and the southwestern regions there were significant increment in vegetation from 2010 to 2015.

Table 5. Statistics of vegetation cover from 2010 to 2015 and from 2000 to 2015 at regional scale

\begin{tabular}{c|c|c|c|c|c|c|c|c}
\hline \multirow{2}{*}{ Regions } & \multicolumn{9}{|c|}{$\mathbf{2 0 1 0 - 2 0 1 5}$} & \multicolumn{4}{c}{$\mathbf{2 0 0 0 - 2 0 1 5}$} \\
\cline { 2 - 8 } & No & Low & Medium & High & No & Low & Medium & High \\
\hline \multirow{2}{*}{ N } & -4070.48 & 24106.01 & 34693.1 & -54749.9 & -82827.5 & -67318 & 8874.36 & 141376.1 \\
E & 572.62 & 744.32 & 121306.7 & -122686 & 1133.58 & -1489.59 & 24647.34 & -24384.9 \\
NE & 2608.59 & -235.53 & 11289.59 & -14179.7 & 1674.94 & -15089.1 & -83364.9 & 96267.69 \\
NW & -7846.14 & 11572.6 & -77238.5 & 73420 & -146291 & -7807.24 & 46606.58 & 107390.5 \\
S & -1686.47 & -40159.1 & -91273.5 & 133147.3 & 154.14 & 7493.07 & 55947.63 & -63622.3 \\
SW & 24165.9 & -76033.4 & -101014 & 201258.7 & -23526.7 & 35620.57 & -26891.6 & 14787.68 \\
SC & 590.23 & -6027.38 & 9805.71 & -4366.68 & 1003.57 & 1959.6 & 22442.54 & -25405.1 \\
\hline
\end{tabular}


From 2000 to 2015, the results of the study illustrated that there was a general decrease of No cover areas in the northern, southwestern and northwestern regions; while High cover areas showed a significant improvement over the fifteen years (Table 5). This may be as a result of the efforts made by the local and central governments to improve forest. On the contrary, the southern, eastern and south central regions recorded a reduction in vegetation cover with $-63622.3 \mathrm{~km}^{2},-24384.9 \mathrm{~km}^{2}$ and $25405.1 \mathrm{~km}^{2}$, respectively. The results can be concluded as having experienced a sawtooth trend in each class of vegetation for the fifteen years study period.

Trend in changes of vegetation cover over the period of 2000 to 2015 at provincial level

Table Al shows the changes in vegetation areas from 2000 to 2005 for each municipalities, autonomous cities and provinces of China. The results revealed that vegetation cover decreased, as shown in the High cover class, in some provinces such as Heilongjiang, Henan, Guangxi, and Qinghai with -16550.09 km², $-12110.08 \mathrm{~km}^{2}$, $131949.5 \mathrm{~km}^{2},-12105.383 \mathrm{~km}^{2}$, accordingly. However, other provincial levels demonstrated an increase of green vegetation during the same period. For instance, Inner Mongolia, Hebei, Sichuan, and Gansu with $17822.12 \mathrm{~km}^{2}, 26496 \mathrm{~km}^{2}$, $29867.89 \mathrm{~km}^{2}$, and $9522.64 \mathrm{~km}^{2}$, respectively.

Similarly, changes in vegetation for the years 2005 to 2010 were produced and presented in Table A1. The data shows that numerous municipalities, autonomous cities and provinces which demonstrated a decrease in vegetation in previous years (20002005) had a significant increase in High cover class; for example Heilongjiang, Henan and Anhui. Furthermore, most provinces experienced significant reduction in No cover areas such as Xizang and Qinghai with $-48234.65 \mathrm{~km}^{2}$ and $-21019.3 \mathrm{~km}^{2}$. Nevertheless, most of provinces indicated an obvious change in both No and High cover classes.

For the years 2010-2015, our findings show that No cover class representing barren lands or built-up areas have escalated in Heilongjiang, Qinghai and Gansu with $212.41 \mathrm{~km}^{2}, 4932.93 \mathrm{~km}^{2}$, and $3985 \mathrm{~km}^{2}$; whereas most of the provinces reveal an increase in vegetation cover as referred to High cover class (Table A2).

In general, the results indicated an improvement in vegetation cover for many provinces; for instance Xinjiang, Heilongjiang, Jilin, Liaoning, Shaanxi and Gansu over the period of study. Even though there were huge reclamation of vegetation, provinces like Guangxi, Guangdong, Fujian, Jiangxi, Hunan, and Hubei showed degradation of forest zones mainly located in eastern and southern China as shown in Table A2.

\section{Discussion}

The continuous estimation and analysis of vegetation cover changes at different scales is a crucial tool for an in-depths understanding of the changes that happened in the ecosystem. This aims to establish a link with all ecosystem components and to acknowledge the driving factors that caused these changes. As aforementioned, remote sensing data has been demonstrated to be one of the best and widely applied methods used in several studies to assess changes in vegetation cover and the ecosystem (Guo et al., 2016; Lyon et al., 1998; Jia et al., 2014).

At the national level, the findings demonstrated that vegetation cover areas have risen throughout China. The analysis of vegetation trends revealed that in 2000, the vegetation cover was less dense than that observed in 2015 with $38.44 \%$ and $41.03 \%$, respectively (Table 3 ). These changes are mainly reflected by the conversion in areas 
from the No and Low cover classes to Medium or High cover classes in 2015 (Table 3). The slight evolution of forest land by $2.36 \%$ (Table 3 ) observed during the study period may be the results of greater efforts undertaken by the central government to conduct environmental restoration projects, particularly to increase green vegetation throughout the country. These results are consistent with studies (Xu et al., 2018) who indicated that $83.34 \%$ of China's territory are experiencing a general increase in vegetation due to environmental restoration projects. Recently, the $9^{\text {th }}$ National Forest Inventories (NFI) revealed that there was an increase of forest lands (National Forestry and Grassland Administration, 2019). Similarly, Liang et al. (2018) indicated a rise in forest areas with 3.60 million ha over the 25 years of study (1982-2006) or 0.15 million ha/year. Besides these successes, the government has also promulgated a series of laws aimed at strengthening environmental restoration and management measures (Chunmei and Zhaolan, 2010; Sims, 1999; Zhang et al., 2007). For example, the Environmental Protection Law which has been formed to lead to ecological protection while industrial development will still be undertaken (Zwierzchowski and Rott-Pietrzyk, 2020; Mu et al., 2014).

Further, several other green building projects have been implemented such as "Pastureland to Grassland", "Shelterbelt", and "Grain to Green" with the same goal of improving vegetation conditions and to reduce human pressure on the ecosystem (Bennett and Smith, 2017; Xu et al., 2017). With the establishment of these projects, a significant change of forest areas has been recorded in the different zones where they have been carried out in China (Zhang et al., 2018; Li et al., 2018). Additionally, the growth in forest lands detected in these study areas may be as a result of climate change experienced in recent years around the globe including China. The contribution of climate change was explained by various authors that global warming has favored the lengthening of the vegetative season and also has increased the photosynthesis capacity of plants in non-arid areas. This has greatly influenced the growth in forests, grassland and the reduction of barren areas (Niemand et al., 2005; Piao et al., 2007, 2008; Arellano et al., 2015; Xu et al., 2014). Contradictorily, some authors declared a decrease in vegetation cover. According to Cao et al. (2011) vegetation lost in China has been intensified because of the unchecked reforestation projects. This lost is due to the fact that they do not take into account local conditions (pedology, hydrology or climate factors) and the use of unsuitable tree species in the regions which could not adapt to soil or weather conditions.

At regional level, the results (Table 5) indicated that the southern, south-central, and eastern regions have decreased in vegetation cover areas, over the fifteen years, with $63622.3 \mathrm{~km}^{2},-25405.1 \mathrm{~km}^{2}$, and $-24384.9 \mathrm{~km}^{2}$, respectively. Even though some studies indicated an increase in vegetation cover in these regions as a results of vegetation restoration projects (Wang et al., 2015). These three regions are among the most urbanized, populated, and developed regions in China. Therefore, the intense activities occurring may be due to changes in vegetation cover. For instance, a progressive reduction in green areas in the eastern were detected in Tables 4 and 5. These results are consistent with studies carried out by several authors in the eastern region. They noted that the excessive resource utilization, the conversion of forest to cropland and the increase in built-up areas have greatly impacted the urban and non-urban forest areas (Fan et al., 2015; Song et al., 2018; Zhang and Huang, 2019). Furthermore, studies showed that the high rate of population density increase of this region, with 503 persons 
per $\mathrm{km}^{2}$ in 2000 to 566 persons per $\mathrm{km}^{2}$ in 2010, has also contributed the decrease in vegetation areas (Yu et al., 2018).

In addition, topography and climate may also act as driving forces for vegetation change. Topography influences vegetation distribution and density (Xin and $\mathrm{Xu}, 2007$; Pan et al., 2003). As mentioned previously in Table 1, China has various terrain structure such as plains and plateaus which may be the cause of fast vegetation degradation. According to Zhao et al. (2014), forest lands are more dense in the upper terrain than in lower elevation. These low elevations facilitate access to human-being for resources extraction which might result to fast vegetation alteration in the east, south and south-central regions of our study area. Furthermore, several studies have stated that changes in climate conditions in China plays a crucial role in vegetation distribution. This is mainly due to the fact that temperature and precipitation changes with time and hence have great impact on vegetation cover growth in several regions, including the southern and eastern China's regions (Wang et al., 2019; Xu et al., 2014).

In contrast, the north, northeast, and northwest regions showed significant growth of vegetation cover over the fifteen years period, with $141376.1 \mathrm{~km}^{2}, 96267.69 \mathrm{~km}^{2}$, and $107390.5 \mathrm{~km}^{2}$, accordingly. Our findings agree with ShengPei et al. (2011) and Wei et al. (2018) who carried out studies on vegetation cover in the northwestern of China from 1982 to 2006 and 2000 to 2010, respectively. The increase in vegetation was illustrated with a rise in NDVI values over the study period due to barren lands reduction by $40,925 \mathrm{~km}^{2}$ and forest improvement of $10 \%$ (ShengPei et al., 2011). Going further, both research indicated that grassland and forestland expansion in the northwestern China, was as a consequence of the Three-North Shelterbelt, Return Cultivated Land for Forest Land and Grass Land Projects.

At the provincial level, the results of 34 provinces, including autonomous cities and municipalities, were shown in Tables $A 1$ and $A 2$ with a constant five-year interval. The results depicted an obvious difference in each province. From the year 2000 to 2015, High cover areas evolved slightly in Xinjiang, Inner Mongolia, Gansu, Yunnan and Shandong provinces, with $40239.77 \mathrm{~km}^{2}, 60650.32 \mathrm{~km}^{2}, 33835.56 \mathrm{~km}^{2}, 39962.94 \mathrm{~km}^{2}$, and $33020.3 \mathrm{~km}^{2}$, respectively as indicated in Table A2. Additionally, some provinces such as Guangdong, Guangxi and Jiangxi showed irregular changes or a reduction in vegetation cover over the 15-year period. Our results are in conformity with a study carried out by $\mathrm{Hu}$ et al., (2019) and Zhang et al. (2020). Their results showed that Guangdong, Guangxi and Jiangxi had decreased in green cover; whereas in Inner Mongolia and Yunnan there was an increase. However, other studies indicated that Jiangxi has demonstrated a slight increase of vegetation due to reforestation projects, and a significant forest loss in Inner Mongolia due to rainfall and temperature change (Xu et al., 2014; Song et al., 2018).

Studies have explained the cause of vegetation cover change at provincial level in China as a consequence of various factors such as migration and population growth. Most of these studies are focused on human activities due to the rapid development that occurs in China since their economic reform. These factors influenced land use change in several ways. In China, the migration of population from rural to urban regions has brought about a significant increase in population density. This has also led to demand for land and raw materials causing a decrease in urban forests areas and grasslands (Walker et al., 2000; Barbieri and Carr, 2005; Carr, 2009; Zhou et al., 2014), and the degradation of ecosystems resources (Wang et al., 2014; Liu et al., 2014). For example, it was indicated that Guangdong province experienced a rapid growth of population 
mainly attributed to fast economic expansion and geographical conditions which has impacted vegetation cover growth in suburban areas (Li et al., 2013a). In addition, an investigation conducted in Guangxi province also illustrated that population growth has influenced the transition of forestland and grassland to urban areas from 1990 to 2017 (Hu et al., 2019). Therefore, these examples show how human activities are the key to drastic vegetation cover loss in some provinces or municipalities in China.

It has also been shown that vegetation and weather conditions are interrelated (Xia et al., 2007). To be more precise, vegetation is sensitive to microclimate variations, thus this may have probably contributed to the vegetation cover changes of each province where there were changes depicted in High cover class.

\section{Conclusion}

Ecosystem health is determined by vegetation cover conditions. Therefore, providing information on the vegetation cover changes constitute an important and fundamental guideline for monitoring the environment. Implementation of effective laws with the purpose of protecting the vegetation from anthropogenic pressure as well as from natural pressure is vital. This research determined the spatial and temporal evolution trend of the vegetation cover in China by using MODIS NDVI data over a period of fifteen years. The study indicated a general trend of vegetation cover at national level in terms of increase in forestland and grasslands. Notwithstanding, the reduction of vegetation cover observed within the study area (regional and provincial levels) may be the results of several driving factors such as rapid population growth, climatic change, urbanization and fast development that occurred in China which need deeper investigations. The results of this study constitute a reference point for future research and a decision-making tool for ecosystems management and restoration. Future research should therefore focus on: (i) a more in-depth study of China's vegetation cover using other satellite products and classification methods which can provide the current and future vegetations conditions and in situ observations. (ii) More research of the driving factors that induce vegetation cover changes at three different levels. (iii) at the provincial level, local policymakers ought to strengthen environmental laws and measures in order to maintain vegetation recovery where there were rise in forest areas, for instance Xinjiang and Yunnan. (iv) However, Guangdong and Guangxi (with huge vegetation loss) need to implement more restoration projects which will essentially focus on forest growth.

Acknowledgements. The authors would like to acknowledge the National Key R\&D Program of China (2017YFD0201804 and 2016YFD0200403) for their financial support.

\section{REFERENCES}

[1] Arellano, P., Tansey, K., Balzter, H., Boyd, D. S. (2015): Detecting the effects of hydrocarbon pollution in the Amazon forest using hyperspectral satellite images. Environmental Pollution 205: 225-239.

[2] Arima, E. Y., Walker, R. T., Perz, S. G., Caldas, M. (2005): Loggers and forest fragmentation: Behavioral models of road building in the Amazon basin. - Annals of the Association of American Geographers 95: 525-541. 
[3] Bao, G., Qin, Z., Bao, Y., Zhou, Y., Li, W., Sanjjav, A. (2014): NDVI-based long-term vegetation dynamics and its response to climatic change in the Mongolian Plateau. Remote Sensing 6: 8337-8358.

[4] Barbieri, A. F., Carr, D. L. (2005): Gender-specific out-migration, deforestation and urbanization in the Ecuadorian Amazon. - Global and Planetary Change 47: 99-110.

[5] Beck, P. S., Atzberger, C., Høgda, K. A., Johansen, B., Skidmore, A. K. (2006): Improved monitoring of vegetation dynamics at very high latitudes: a new method using MODIS NDVI. - Remote sensing of Environment 100: 321-334.

[6] Bennett, M. M., Smith, L. C. (2017): Advances in using multitemporal night-time lights satellite imagery to detect, estimate, and monitor socioeconomic dynamics. - Remote Sensing of Environment 192: 176-197.

[7] Bozkaya, A. G., Balcik, F. B., Goksel, C., Esbah, H. (2015): Forecasting land-cover growth using remotely sensed data: a case study of the Igneada protection area in Turkey. - Environmental Monitoring and Assessment 187: 59.

[8] Burden, R., Randerson, P. (1972): Quantitative studies of the effects of human trampling on vegetation as an aid to the management of semi-natural areas. - Journal of Applied Ecology 439-457.

[9] Caldas, M., Walker, R., Arima, E., Perz, S., Aldrich, S., Simmons, C. (2007): Theorizing land cover and land use change: the peasant economy of Amazonian deforestation. - Annals of the Association of American Geographers 97: 86-110.

[10] Cao, S., Chen, L., Shankman, D., Wang, C., Wang, X., Zhang, H. (2011): Excessive reliance on afforestation in China's arid and semi-arid regions: lessons in ecological restoration. - Earth-Science Reviews 104: 240-245.

[11] Caputo, J. (2009): Sustainable Forest Biomass: Promoting Renewable Energy and Forest Stewardship. - EESI, Washington, DC.

[12] Carlson, T. N., Ripley, D. A. (1997): On the relation between NDVI, fractional vegetation cover, and leaf area index. - Remote Sensing of Environment 62: 241-252.

[13] Carr, D. (2009): Population and deforestation: why rural migration matters. - Progress in Human Geography 33: 355-378.

[14] Chunmei, W., Zhaolan, L. (2010): Environmental policies in China over the past 10 years: progress, problems and prospects. - Procedia Environmental Sciences 2: 17011712.

[15] Coppin, P., Jonckheere, I., Nackaerts, K., Muys, B., Lambin, E. 2004. Review ArticleDigital change detection methods in ecosystem monitoring: a review. International Journal of Remote Sensing 25: 1565-1596.

[16] Fan, J., Liu, J., Zhang, X., Cumtb, B. (2015): Urbanization effect on regional household energy consumption in China. - China Population Resources Environment 1: 55-60.

[17] FAO (1997): Estimating Biomass and Biomass Change in Tropical Forests. - FAO, Rome.

[18] Fensholt, R., Sandholt, I. (2005): Evaluation of MODIS and NOAA AVHRR vegetation indices with in situ measurements in a semi-arid environment. - International Journal of Remote Sensing 26: 2561-2594.

[19] Fensholt, R., Sandholt, I., Stisen, S. (2006): Evaluating MODIS, MERIS, and VEGETATION vegetation indices using in situ measurements in a semiarid environment. - IEEE Transactions on Geoscience and Remote Sensing 44: 1774-1786.

[20] Gillespie, T. W., Ostermann-Kelm, S., Dong, C., Willis, K. S., Okin, G. S., Macdonald, G. M. (2018): Monitoring changes of NDVI in protected areas of southern California. Ecological Indicators 88: 485-494.

[21] Gu, X., Li, W., Wang, L. 2016. Understanding vegetation changes in northern China and Mongolia with change vector analysis. - SpringerPlus 5: 1780.

[22] Guo, H., Huang, Y., Li, X. (2016): Dynamic changes of fractional vegetation cover along the mainstream of the Tarim River. - Journal of Desert Research 36: 1472-1480. 
[23] Gutman, G., Huang, C., Chander, G., Noojipady, P., Masek, J. G. (2013): Assessment of the NASA-USGS global land survey (GLS) datasets. - Remote Sensing of Environment 134: 249-265.

[24] Hashim, H., Abd Latif, Z., Adnan, N. A. (2019): Urban vegetation classification with NDVI threshold value method with very high resolution (VHR) PLEIADES Imagery. Int. Arch. Photogramm. - Remote Sens. Spat. Inf. Sci. 237-240.

[25] Hu, Y., Zhen, L., Zhuang, D. (2019): Assessment of land-use and land-cover change in Guangxi, China. - Scientific Reports 9: 1-13.

[26] Hutchinson, J. (1969): Population and Food Supply. - Cambridge University Press, Cambridge.

[27] Islam, K., Jashimuddin, M., Nath, B., Nath, T. K. (2018): Land use classification and change detection by using multi-temporal remotely sensed imagery: the case of Chunati wildlife sanctuary, Bangladesh. - The Egyptian Journal of Remote Sensing and Space Science 21: 37-47.

[28] Jacinthe, P.-A., Lal, R. (2006): Spatial variability of soil properties and trace gas fluxes in reclaimed mine land of southeastern Ohio. - Geoderma 136: 598-608.

[29] Jacquin, A., Sheeren, D., Lacombe, J.-P. (2010): Vegetation cover degradation assessment in Madagascar savanna based on trend analysis of MODIS NDVI time series. - International Journal of Applied Earth Observation and Geoinformation 12: S3-S10.

[30] Janetos, A., Justice, C. (2000): Land cover and global productivity: a measurement strategy for the NASA programme. - International Journal of Remote Sensing 21: 1491-1512.

[31] Jensen, J. R. (1996): Introductory Digital Image Processing: A Remote Sensing Perspective. - Prentice-Hall Inc, Upper Saddle River, NJ.

[32] Jia, Y., Yu, G., He, N., Zhan, X., Fang, H., Sheng, W., Zuo, Y., Zhang, D., Wang, Q. (2014): Spatial and decadal variations in inorganic nitrogen wet deposition in China induced by human activity. - Scientific Reports 4: 1-7.

[33] Kaimowitz, D., Angelsen, A. (1998): Economic Models of Tropical Deforestation: A Review. - CIFOR, Bogor.

[34] Kashaigili, J. J., Mbilinyi, B. P., MCcartney, M., Mwanuzi, F. L. (2006): Dynamics of Usangu plains wetlands: use of remote sensing and GIS as management decision tools. - Physics and Chemistry of the Earth, Parts A/B/C 31: 967-975.

[35] Kauppi, P. E., Ausubel, J. H., Fang, J., Mather, A. S., Sedjo, R. A., Waggoner, P. E. (2006): Returning forests analyzed with the forest identity. - Proceedings of the National Academy of Sciences 103: 17574-17579.

[36] Kerbiriou, C., Leviol, I., Jiguet, F., Julliard, R. (2008): The impact of human frequentation on coastal vegetation in a biosphere reserve. - Journal of Environmental Management 88: 715-728.

[37] Lambin, E. F. (1994): Modelling Deforestation Processes. A Review. - Research Report, Joint Research Center, Institute for Remote Sensing Applications; European Space Agency, Luxembourg.

[38] Lambin, E. F., Strahler, A. H. (1994): Indicators of land-cover change for changevector analysis in multitemporal space at coarse spatial scales. - International Journal of Remote Sensing 15: 2099-2119.

[39] Li, C., Kuang, Y., Huang, N., Zhang, C. (2013a): The long-term relationship between population growth and vegetation cover: an empirical analysis based on the panel data of 21 cities in Guangdong province, China. - International Journal of Environmental Research and Public Health 10: 660-677.

[40] Li, X., Zhang, B., Jin, Z. (2013b): Dynamic monitoring of vegetation coverage change in Hedong Area of Gansu based on MODIS-NDVI. - Research of Soil and Water Conservation 20: 112-115+307. 
[41] Li, D., Xu, D., Wang, Z., You, X., Zhang, X., Song, A. (2018): The dynamics of sandstabilization services in Inner Mongolia, China from 1981 to 2010 and its relationship with climate change and human activities. - Ecological Indicators 88: 351-360.

[42] Liang, L., Chen, F., Shi, L., Niu, S. (2018): NDVI-derived forest area change and its driving factors in China. - PloS ONE 13.

[43] Liping, C., Yujun, S., Saeed, S. (2018): Monitoring and predicting land use and land cover changes using remote sensing and GIS techniques - a case study of a hilly area, Jiangle, China. - PloS ONE 13.

[44] Liu, X., Ma, L., Li, X., Ai, B., Li, S., He, Z. (2014): Simulating urban growth by integrating landscape expansion index (LEI) and cellular automata. - International Journal of Geographical Information Science 28: 148-163.

[45] Liu, H., Zheng, L., Yin, S. (2018): Multi-perspective analysis of vegetation cover changes and driving factors of long time series based on climate and terrain data in Hanjiang River Basin, China. - Arabian Journal of Geosciences 11: 509.

[46] Louise, L., Agnès, B., Danny, L. S. (2014): Regional analysis of crop and natural vegetation in West Africa based on NDVI metrics. - 2014 IEEE Geoscience and Remote Sensing Symposium, IEEE 5107-5110.

[47] Lu, D. (2006): The potential and challenge of remote sensing-based biomass estimation. - International Journal of Remote Sensing 27: 1297-1328.

[48] Lu, D., Mausel, P., Brondizio, E., Moran, E. (2004): Change detection techniques. International Journal of Remote Sensing 25: 2365-2401.

[49] Lucas-Borja, M., Bastida, F., Moreno, J., Nicolás, C., Andres, M., Lopez, F., del cerro, A. (2011): The effects of human trampling on the microbiological properties of soil and vegetation in Mediterranean mountain areas. - Land Degradation \& Development 22: 383-394.

[50] Lunetta, R. S., Knight, J. F., Ediriwickrema, J., Lyon, J. G., Worthy, L. D. (2006): Land-cover change detection using multi-temporal MODIS NDVI data. - Remote Sensing of Environment 105: 142-154.

[51] Lyon, J. G., Yuan, D., Lunetta, R. S., Elvidge, C. D. (1998): A change detection experiment using vegetation indices. - Photogrammetric Engineering and Remote Sensing 64: 143-150.

[52] Madonsela, S., Cho, M. A., Ramoelo, A., Mutanga, O., Naidoo, L. (2018): Estimating tree species diversity in the savannah using NDVI and woody canopy cover. International Journal of Applied Earth Observation and Geoinformation 66: 106-115.

[53] Mao, D., Wang, Z., Song, K., Liu, D., Zhang, B., Zhang, S., Luo, L., Zhang, C. (2011): The vegetation NDVI variation and its responses to climate change and LUCC from 1982 to 2006 year in northeast permafrost region. - China Environmental Science 31: 283-292.

[54] Mooney, H. A., Duraiappah, A., Larigauderie, A. (2013): Evolution of natural and social science interactions in global change research programs. - Proceedings of the National Academy of Sciences 110: 3665-3672.

[55] Moroni, M. (2013): Simple models of the role of forests and wood products in greenhouse gas mitigation. - Australian Forestry 76: 50-57.

[56] Mu, S., Li, J., Chen, Y., Gang, C., Zhou, W., Ju, W. (2012): Spatial differences of variations of vegetation coverage in Inner Mongolia during 2001-2010. - Acta Geographica Sinica 67: 1255-1268.

[57] Mu, Z., Bu, S., Xue, B. (2014): Environmental legislation in China: achievements, challenges and trends. - Sustainability 6: 8967-8979.

[58] National Forestry and Grassland Administration (2019): Forest Resources in China: The 9th National Forest Inventory. - NFGA, Beijing.

[59] Niemand, C., Köstner, B., Prasse, H., Grünwald, T., Bernhofer, C. (2005): Relating tree phenology with annual carbon fluxes at Tharandt forest. - Meteorologische Zeitschrift 14: 197-202. 
[60] Obienusi, E., Ekezie, M., Onwuka, S. (2014): Investigating the place of population increase and level of income earning in food security a study of yam supply in Awka urban, Anambra state of Nigeria. - J. Nat. Sci. Res 11: 11-21.

[61] Pacheco, P., Poccard-Chapuis, R. (2012): The complex evolution of cattle ranching development amid market integration and policy shifts in the Brazilian Amazon. Annals of the Association of American Geographers 102: 1366-1390.

[62] Pan, Y., Li, X., Gong, P., He, C., Shi, P., Pu, R. (2003): An integrative classification of vegetation in China based on NOAA AVHRR and vegetation-climate indices of the Holdridge life zone. - International Journal of Remote Sensing 24: 1009-1027.

[63] Peng, D., Zhang, B., Liu, L., Fang, H., Chen, D., Hu, Y., Liu, L. (2012): Characteristics and drivers of global NDVI-based FPAR from 1982 to 2006. - Global Biogeochemical Cycles 26.

[64] Peng, J., Li, Y., Tian, L., Liu, Y., Wang, Y. (2015): Vegetation dynamics and associated driving forces in Eastern China during 1999-2008. - Remote Sensing 7: 13641-13663.

[65] Piao, S., Fang, J., Zhou, L., Guo, Q., Henderson, M., Ji, W., Li, Y., Tao, S. (2003): Interannual variations of monthly and seasonal normalized difference vegetation index (NDVI) in China from 1982 to 1999. - Journal of Geophysical Research: Atmospheres 108. DOI: $10.1029 / 2002 J D 002848$.

[66] Piao, S., Friedlingstein, P., Ciais, P., Viovy, N., Demarty, J. (2007): Growing season extension and its impact on terrestrial carbon cycle in the Northern Hemisphere over the past 2 decades. - Global Biogeochemical Cycles 21. DOI: 10.1029/2006gb002888.

[67] Piao, S., Ciais, P., Friedlingstein, P., Peylin, P., Reichstein, M., Luyssaert, S., Margolis, H., Fang, J., Barr, A., Chen, A. (2008): Net carbon dioxide losses of northern ecosystems in response to autumn warming. - Nature 451: 49-52.

[68] Piao, S., Fang, J., Ciais, P., Peylin, P., Huang, Y., Sitch, S., Wang, T. (2009): The carbon balance of terrestrial ecosystems in China. - Nature 458: 1009-1013.

[69] Piao, S., Wang, X., Ciais, P., Zhu, B., Wang, T., Liu, J. (2011): Changes in satellite-derived vegetation growth trend in temperate and boreal Eurasia from 1982 to 2006. - Global Change Biology 17: 3228-3239.

[70] Ratcliffe, D. A. (1984): Post-medieval and recent changes in British vegetation: the culmination of human influence. - New Phytologist 98: 73-100.

[71] Sahebjalal, E., Dashtekian, K. (2013): Analysis of land use-land covers changes using normalized difference vegetation index (NDVI) differencing and classification methods. - African Journal of Agricultural Research 8: 4614-4622.

[72] Sasaki, N., Takahara, H. (2011): Late Holocene human impact on the vegetation around Mizorogaike Pond in northern Kyoto Basin, Japan: a comparison of pollen and charcoal records with archaeological and historical data. - Journal of Archaeological Science 38: 1199-1208.

[73] Scanlon, T. M., Albertson, J. D., Caylor, K. K., Williams, C. A. (2002): Determining land surface fractional cover from NDVI and rainfall time series for a savanna ecosystem. - Remote Sensing of Environment 82: 376-388.

[74] Shengpei, D., Zhang, B., Haijun, W., Yamin, W., Lingxia, G., Xingmei, W., Dan, L. (2011): Vegetation cover change and the driving factors over northwest China. Journal of Arid Land 3: 25-33.

[75] Sheram, K. (1993): The Environmental Data Book: A Guide to Statistics on the Environment and Development. - World Bank, Washington, DC.

[76] Shu, W., Ximing, Y. (2018): How China's Grain-for-Green Project Contributes to Farmers' Income Growth. - China Economist 13: 88-102.

[77] Sims, H. (1999): One-fifth of the sky: China's environmental stewardship. - World Development 27: 1227-1245. 
[78] Skole, D., Justice, C., Townshend, J., Janetos, A. (1997): A land cover change monitoring program: strategy for an international effort. - Mitigation and Adaptation Strategies for Global Change 2: 157-175.

[79] Song, X.-P., Hansen, M. C., Stehman, S. V., Potapov, P. V., Tyukavina, A., Vermote, E. F., Townshend, J. R. (2018): Global land change from 1982 to 2016. - Nature 560: 639-643.

[80] Sterling, S. M., Ducharne, A., Polcher, J. (2013): The impact of global land-cover change on the terrestrial water cycle. - Nature Climate Change 3: 385-390.

[81] Tucker, C. J. (1979): Red and photographic infrared linear combinations for monitoring vegetation. - Remote Sensing of Environment 8: 127-150.

[82] United Nations (2017): World Urbanization Prospects: The 2017 Revision. - UN Department of Economic and Social Affairs Population Division, New York.

[83] Usman, M., Liedl, R., Shahid, M., Abbas, A. (2015): Land use/land cover classification and its change detection using multi-temporal MODIS NDVI data. - Journal of Geographical Sciences 25: 1479-1506.

[84] Veraverbeke, S., Gitas, I., Katagis, T., Polychronaki, A., Somers, B., Goossens, R. (2012): Assessing post-fire vegetation recovery using red-near infrared vegetation indices: accounting for background and vegetation variability. - ISPRS Journal of Photogrammetry and Remote Sensing 68: 28-39.

[85] Vitousek, P. M., Mooney, H. A., Lubchenco, J., Melillo, J. M. (1997): Human domination of Earth's ecosystems. - Science 277: 494-499.

[86] Walker, R., Moran, E., Anselin, L. (2000): Deforestation and cattle ranching in the Brazilian Amazon: external capital and household processes. - World Development 28: 683-699.

[87] Wang, L. (2010): The changes of China's environmental policies in the latest 30 years. - Procedia Environmental Sciences 2: 1206-1212.

[88] Wang, G., Han, L., Tang, X., Jin, Z. (2012): Temporal and spatial variation of vegetation in the Jinsha River basin. - Resources and Environment in the Yangtze Basin 21: 1191-1196.

[89] Wang, J., Yan, Q., Liu, Z., Luo, C. (2013): Analysis on the change of vegetation coverage in Qinghai province from 2000 to 2012. - ISPRS - International Archives of the Photogrammetry, Remote Sensing and Spatial Information Sciences 1: 121-126.

[90] Wang, S., Ma, H., Zhao, Y. (2014): Exploring the relationship between urbanization and the eco-environment-a case study of Beijing-Tianjin-Hebei region. - Ecological Indicators 45: 171-183.

[91] Wang, J., Wang, K., Zhang, M., Zhang, C. (2015): Impacts of climate change and human activities on vegetation cover in hilly southern China. - Ecological Engineering 81: 451-461.

[92] Wang, W., Li, C., Shu, J., Chen, W. (2019): Changes of vegetation in southern China. Science China Earth Sciences 62: 1316-1328.

[93] Wei, Q., Qingke, Z., Xuexia, Z. (2006): Review of vegetation covering and its measuring and calculating method. - Journal of Northwest Sci-Tech University of Agriculture and Forestry.

[94] Wei, X., Wang, S., Wang, Y. (2018): Spatial and temporal change of fractional vegetation cover in North-western China from 2000 to 2010. - Geological Journal 53: 427-434.

[95] Weng, Q. (2001): Modeling urban growth effects on surface runoff with the integration of remote sensing and GIS. - Environmental Management 28: 737-748.

[96] Xia, K., Zhang, L., Yang, J. (2007): Correlation analysis between land cover change and climate change in Zhejiang province. - Geoinformatics 2007: Geospatial Information Science, International Society for Optics and Photonics 675339. https://doi.org/10.1117/12.763556. 
[97] Xin, Z., Xu, J. (2007): Spatial and temporal evolution of vegetation cover in the Loess Plateau and its response to climate change. - Progress in Natural Science 17: 770-778.

[98] Xu, G., Zhang, H., Chen, B., Zhang, H., Innes, J. L., Wang, G., Yan, J., Zheng, Y., Zhu, Z., Myneni, R. B. (2014): Changes in vegetation growth dynamics and relations with climate over China's landmass from 1982 to 2011. - Remote Sensing 6: 3263-3283.

[99] Xu, G., Zhang, J., Li, P., Li, Z., Lu, K., Wang, X., Wang, F., Cheng, Y., Wang, B. (2018): Vegetation restoration projects and their influence on runoff and sediment in China. - Ecological Indicators 95: 233-241.

[100] Xu, W., Xiao, Y., Zhang, J., Yang, W., Zhang, L., Hull, V., Wang, Z., Zheng, H., Liu, J., Polasky, S. (2017): Strengthening protected areas for biodiversity and ecosystem services in China. - Proceedings of the National Academy of Sciences 114: 1601-1606.

[101] Yan, J., Qiao, M., Zhou, H., Zhou, S., Lou, L., Song, P. (2013): Vegetation dynamics in Ili River valley of Xinjiang based on MODIS/NDVI. - Arid Land Geography 36: 512519.

[102] Yan, L., He, R., Kašanin-Grubin, M., Luo, G., Peng, H., Qiu, J. (2017): The dynamic change of vegetation cover and associated driving forces in Nanxiong Basin, China. Sustainability 9: 443.

[103] Yang, J., Weisberg, P. J., Bristow, N. A. (2012): Landsat remote sensing approaches for monitoring long-term tree cover dynamics in semi-arid woodlands: comparison of vegetation indices and spectral mixture analysis. - Remote Sensing of Environment 119: 62-71.

[104] Yu, S., Zhang, Z., Liu, F. (2018): Monitoring population evolution in China using timeseries DMSP/OLS nightlight imagery. - Remote Sensing 10: 194.

[105] Zhang, X., Wu, B. (2015): A temporal transformation method of fractional vegetation cover derived from high and moderate resolution remote sensing data. - Acta Ecologica Sinica 35: 1155-1164.

[106] Zhang, K., Zongguo, W., Liying, P. (2007): Environmental policies in China: evolvement, features and evaluation. - China Population, resources and Environment 17: $1-7$.

[107] Zhang, H. K., Roy, D. P., Yan, L., Li, Z., Huang, H., Vermote, E., Skakun, S., Roger, J.-C. (2018): Characterization of Sentinel-2A and Landsat-8 top of atmosphere, surface, and nadir BRDF adjusted reflectance and NDVI differences. - Remote Sensing of Environment 215: 482-494.

[108] Zhang, M., Wang, J., Li, S. (2019): Tempo-spatial changes and main anthropogenic influence factors of vegetation fractional coverage in a large-scale opencast coal mine area from 1992 to 2015. - Journal of Cleaner Production 232: 940-952.

[109] Zhang, X., Xie, H., Shi, J., Lv, T., Zhou, C., Liu, W. (2020): Assessing changes in ecosystem service values in response to land cover dynamics in Jiangxi Province, China. - International Journal of Environmental Research and Public Health 17: 3018.

[110] Zhang, Y., Li, L., Wang, H., Zhang, Y., Wang, N., Chen, J. (2017): Land surface phenology of northeast China during 2000-2015: temporal changes and relationships with climate changes. - Environmental Monitoring and Assessment 189: 1-13.

[111] Zhao, Y., Tomita, M., Hara, K., Fujihara, M., Yang, Y., Da, L. (2014): Effects of topography on status and changes in land-cover patterns, Chongqing City, China. Landscape and Ecological Engineering 10: 125-135.

[112] Zhou, P., Wen, A.-B., Yan, D.-C., Shi, Z.-L., Guo, J., Ju, Z.-S., Zhang, Y.-L. (2014): Changes in land use and agricultural production structure before and after the implementation of grain for green program in Western China-taking two typical counties as examples. - Journal of Mountain Science 11: 526-534.

[113] Zhou, Y., Zhang, L., Fensholt, R., Wang, K., Vitkovskaya, I., Tian, F. (2015): Climate contributions to vegetation variations in central Asian drylands: pre- and post-USSR collapse. - Remote Sensing 7: 2449-2470. 
[114] Zoungrana, B. J., Conrad, C., Thiel, M., Amekudzi, L. K., Da, E. D. (2018): MODIS NDVI trends and fractional land cover change for improved assessments of vegetation degradation in Burkina Faso, West Africa. - Journal of Arid Environments 153: 66-75.

[115] Zubair, A. O. (2006): Change Detection in Land Use and Land Cover Using Remote Sensing Data and GIS (A Case Study of Ilorin and Its Environs in Kwara State). Department of Geography, University of Ibadan, Ibadan.

[116] Zwierzchowski, J., Rott-Pietrzyk, E. (2020): Polish and Chinese approach to environmental law. - Suleyman Demirel University Bulletin: Social Sciences 53(2): $27-$ 34. https://doi.org/10.47344/sdubss.v53i2.324.

\section{APPENDIX}

Table A1. Changes in area $\left(\mathrm{km}^{2}\right)$ from 2000 to 2005,2005 to 2010

\begin{tabular}{|c|c|c|c|c|c|c|c|c|}
\hline \multirow{2}{*}{ Name } & \multicolumn{4}{|c|}{$2000-2005$} & \multicolumn{4}{|c|}{ 2005-2010 } \\
\hline & No & Low & Medium & High & No & Low & Medium & High \\
\hline Heilongjiang & -442.40 & -1747.15 & 18753.16 & -16550.09 & -95.97 & -1144.1 & -70506.3 & 71728.14 \\
\hline Xinjiang & -47162.31 & 31766.51 & 12741.53 & 2649.54 & -47201.6 & 19249.5 & 16391.93 & 11568.58 \\
\hline Shanxi & -16.71 & -15189.92 & 3569.34 & 11628.23 & -4.04 & -12958.4 & -29346.8 & 42323.52 \\
\hline Ningxia & -631.85 & -4478.22 & 4442.97 & 667.71 & -136.76 & -11225.6 & 8722.93 & 2633.98 \\
\hline Xizang/Tibet & 46199.99 & -28344.07 & -23913.4 & 6048.23 & -48234.7 & 100793.5 & 10842.93 & -63409.4 \\
\hline Shandong & 251.80 & -4595.31 & -6807 & 11144.23 & -279.46 & -1492.56 & -83462.4 & 85234.22 \\
\hline Henan & 16.07 & 452.16 & 11659.68 & -12110.09 & -29.92 & -2323.64 & -50309.3 & 52665.27 \\
\hline Jiangsu & 363.00 & -208.49 & -11185.44 & 11031.65 & 34.8 & -43.72 & -21661 & 21670.19 \\
\hline Anhui & 125.93 & -226.86 & 5559.98 & -5446.39 & -182.77 & -490.43 & -22344.6 & 23011.32 \\
\hline Hubei & 153.06 & -304.57 & -1777.19 & 1931.10 & -62.26 & 792.71 & 16790.71 & -17525.8 \\
\hline Zhejiang & 46.60 & -68.93 & 1516.89 & -1494.33 & -49.35 & 90.75 & 1757.22 & -1805.17 \\
\hline Jiangxi & 213.95 & -322.11 & -86.87 & 196.08 & 134.86 & 3587.46 & 27145.11 & -30882.7 \\
\hline Hunan & -6.20 & 2291.51 & 8875.59 & -11296.57 & 342.59 & 7078.8 & 27397.34 & -34702.4 \\
\hline Yunnan & -1888.43 & -4481.52 & -506.52 & 6890.59 & 1754.63 & 1728.58 & 1226.77 & -4726.41 \\
\hline Guizhou & 6.85 & 2021.74 & -1904.66 & -130.28 & 150.72 & 19252.47 & 39936.64 & -59346.4 \\
\hline Fujian & 41.97 & 38.75 & -0.74 & -74.82 & -70.16 & 1423.74 & 14081.94 & -15447 \\
\hline Guangxi & 888.00 & 32108.96 & 98851.28 & -131949.50 & -20.68 & -5589.91 & -1409.89 & 7096.68 \\
\hline Guangdong & 136.54 & 8050.20 & 29427.39 & -37621.76 & 852.67 & 12941.94 & 18220.42 & -32027.1 \\
\hline Hainan & -18.70 & 186.76 & 5245.4 & -5414.57 & 1.6 & -158.35 & -3484.54 & 3637.03 \\
\hline Jilin & -32.04 & -5450.71 & 10057.7 & -4573.86 & -174.66 & -4835.4 & -19300.3 & 24316.98 \\
\hline Liaoning & -1.41 & -1461.77 & -36969.58 & 39431.44 & -187.18 & -214.41 & 3310.83 & -3905.18 \\
\hline Tianjin & 19.23 & -778.30 & -1388.13 & 2152.95 & -158.83 & -328.89 & -1411.51 & 1899.26 \\
\hline Qinghai & 11719.82 & 11268.25 & -10881.05 & -12105.38 & -21019.3 & -9917.38 & 49879.89 & -18944.7 \\
\hline Gansu & -7407.15 & -3054.56 & 951.13 & 9522.65 & -26529.2 & -2404.88 & 24418.53 & 4503.09 \\
\hline Shaanxi & -47.46 & -16748.66 & 10130.3 & 6658.58 & -29.13 & -33834.8 & 7046.97 & 26816.39 \\
\hline Inner Mongolia & -34301.31 & 14762.72 & 1812.44 & 17822.12 & -44058.3 & -60784.6 & 50980.47 & 53875.95 \\
\hline Chongqing & 2.89 & 327.47 & 2674.28 & -3000.27 & -13.22 & 340.47 & 4227.67 & -4558.19 \\
\hline Hebei & 18.62 & -12998.94 & -13510.15 & 26496.00 & -255 & -3069.34 & -30688.9 & 34010.23 \\
\hline Shanghai & -5.98 & -18.11 & -1147.94 & 1168.62 & 9.67 & -13.58 & -465.92 & 470.65 \\
\hline Beijing & 2.62 & -57.70 & -1846.63 & 1902.68 & -3.29 & -20.72 & -3988.85 & 4015.03 \\
\hline Taiwan & -26.75 & 56.00 & 24.55 & -58.72 & -47.16 & 49.49 & 416.76 & -416.67 \\
\hline Hongkong & 1.351 & 57.712 & 329.48 & -391.917 & -0.16 & 54.83 & 41.63 & -98.45 \\
\hline Sichuan & 624.97 & -1678.27 & -28820.41 & 29867.89 & 2035.47 & 21693.52 & 70358.69 & -94106.9 \\
\hline
\end{tabular}


Table A2. Changes in area $\left(\mathrm{km}^{2}\right)$ from 2010 to 2015,2000 to 2015

\begin{tabular}{|c|c|c|c|c|c|c|c|c|}
\hline \multirow{2}{*}{ Name } & \multicolumn{4}{|c|}{ 2010-2015 } & \multicolumn{4}{|c|}{ 2000-2015 } \\
\hline & No & Low & Medium & High & No & Low & Medium & High \\
\hline Heilongjiang & 2172.41 & 167.39 & 12155.2 & -14501.6 & 1634.04 & -2723.86 & -39598 & 40676.42 \\
\hline Xinjiang & -16776.2 & 13102.49 & -22356.9 & 26021.66 & -111140 & 64118.5 & 6776.54 & 40239.77 \\
\hline Shanxi & 137.13 & -352.69 & 1505.63 & -1291.82 & 116.38 & -28501 & -24271.8 & 52659.93 \\
\hline Ningxia & -1.82 & 4703.63 & -3871.3 & -828.46 & -770.42 & -11000.2 & 9294.6 & 2473.23 \\
\hline Xizang/Tibet & -18018 & -27100.6 & 999.95 & 44125.17 & -20052.7 & 45348.91 & -12070.5 & -13236 \\
\hline Shandong & 150.76 & 281.27 & 62873.39 & -63298.1 & 123.1 & -5806.61 & -27396 & 33080.3 \\
\hline Henan & 49.1 & 1860.06 & 42811.16 & -44724.3 & 35.25 & -11.42 & 4161.54 & -4169.11 \\
\hline Jiangsu & -259.75 & 522.17 & 31182.57 & -31451.5 & 138.05 & 269.96 & -1663.83 & 1250.32 \\
\hline Anhui & 517.91 & 395.41 & 19603.06 & -20518.3 & 461.07 & -321.87 & 2818.43 & -2953.38 \\
\hline Hubei & 597.98 & 642.68 & -5794.74 & 4551.63 & 688.78 & 1130.83 & 9218.78 & -11043 \\
\hline Zhejiang & 56.96 & 2351.72 & 15420.1 & -17827.2 & 54.21 & 2373.54 & 18694.2 & -21126.7 \\
\hline Jiangxi & -248.68 & -2687.82 & -13028.8 & 15827.39 & 100.13 & 577.54 & 14029.43 & -14859.2 \\
\hline Hunan & -56.85 & -8530.12 & -27210.7 & 35805.99 & 279.54 & 840.19 & 9062.22 & -10193 \\
\hline Yunnan & -1570.17 & -11133.4 & -25082.1 & 37798.76 & -1703.97 & -13886.3 & -24361.9 & 39962.94 \\
\hline Guizhou & -108.19 & -16112.1 & -27172.3 & 43409.79 & 49.38 & 5162.09 & 10859.71 & -16066.9 \\
\hline Fujian & 164.7 & -178.55 & 3708.83 & -3692.23 & 136.5 & 1283.94 & 17790.02 & -19214.1 \\
\hline Guangxi & -724.41 & -20401.4 & -55497.6 & 76644.96 & 142.91 & 6117.66 & 41943.75 & -48207.9 \\
\hline Guangdong & -973.57 & -19628 & -34425.4 & 55027.56 & 15.63 & 1364.16 & 13222.4 & -14621.3 \\
\hline Hainan & 12.69 & -16.17 & -981.69 & 989.09 & -4.41 & 12.24 & 779.17 & -788.45 \\
\hline Jilin & 150.05 & -217.4 & 7559.64 & -8009.3 & -56.65 & -10503.5 & -1682.91 & 11733.82 \\
\hline Liaoning & 286.14 & -185.51 & -8425.25 & 8331.2 & 97.55 & -1861.69 & -42084 & 43857.46 \\
\hline Tianjin & 44.23 & 162.45 & 2109.44 & -2315.72 & -95.36 & -944.74 & -690.2 & 1736.5 \\
\hline Qinghai & 4932.93 & -5473.31 & -30939.1 & 31482.33 & -4366.54 & -4122.44 & 8059.72 & 432.26 \\
\hline Gansu & 3985.31 & -4839.22 & -18947.8 & 19809.82 & -29951 & -10298.7 & 6421.88 & 33835.56 \\
\hline Shaanxi & 13.67 & 4079 & -1123.42 & -3065.35 & -62.92 & -46504.4 & 16053.85 & 30409.63 \\
\hline Inner Mongolia & -4360.36 & 23823.58 & -8432.35 & -11047.8 & -82720 & -22198.3 & 44360.56 & 60650.32 \\
\hline Chongqing & 159.43 & -609.48 & -3388.02 & 3831.53 & 149.1 & 58.46 & 3513.93 & -3726.93 \\
\hline Hebei & 108.07 & 439.03 & 34632.26 & -35177.5 & -128.3 & -15629.3 & -9566.81 & 25328.69 \\
\hline Shanghai & -14.26 & 24.16 & 1141.94 & -1151.99 & -10.57 & -7.53 & -471.92 & 487.28 \\
\hline Beijing & 0.45 & 33.64 & 4878.13 & -4917.05 & -0.22 & -44.78 & -957.35 & 1000.66 \\
\hline Taiwan & 204.99 & 35.96 & 405.67 & -647.03 & 131.09 & 141.45 & 846.98 & -1122.43 \\
\hline Hongkong & -1.19 & -113.53 & -368.81 & 485.68 & 0 & -0.99 & 2.31 & -4.69 \\
\hline Sichuan & -4628.94 & -21077.8 & -46371.1 & 72093.5 & -1968.5 & -1062.59 & -4832.8 & 7854.5 \\
\hline
\end{tabular}

